Tarih Kültür ve Sanat Araştırmaları Dergisi (ISSN: 2147-0626)

Journal of History Culture and Art Research

Revue des Recherches en Histoire Culture et Art

مجلة البحوث التاريخية و الثقافية و الفنية
Vol. 1, No. 1, March 2012

Copyright (C) Karabuk University

http://kutaksam.karabuk.edu.tr/index.php

DOI: $10.7596 /$ taksad.v1i1.17

\title{
Açık Dergi Yayıncılı̆ğında Örnek Bir Uygulama: Tarih Külttür ve Sanat Araştırmaları Dergisi
}

Sinan Yllmaz, Karabuk University, Turkey.

Özet

Karabük Üniversitesi Tarih Kültür ve Sanat Araştırmaları Merkezi bünyesinde kurulan Tarih Kültür ve Sanat Araştırmaları Dergisi, Mart 2012 sayısıyla yayın hayatına başladı. Dergimiz, merkezin kuruluş amaçları doğrultusunda sosyal bilimlerin tüm alt branşlarına yönelik hizmet verecektir.

Yılda 4 kez yayımlanacak olan derginin Türkçe, İngilizce, Fransızca ve Arapça ara yüzleri sayesinde bu dillerin her birinde dergiye erişim mümkün olacaktır. Dergide yayımlanan makalelerin dört farklı dilde özetleri bulunacaktır.

Tarih Kültür ve Sanat Araştırmaları Dergisi Açık Dergi Sistemlerine Arapça dil eklentisi ekleyerek bu konuda bir ilki gerçekleştirmiş̧ir. Ayrıca derginin Türkçe ara yüzünde bulunan pek çok problem de titiz bir çalışmayla giderilmiştir. Açık Dergi Sistemlerini kullanan Türkiye'deki kullanıcıların talep etmeleri halinde yapmış olduğumuz çalışmaları kendileriyle paylaşmamız mümkündür. Sistemin Türkçe ara yüzünü daha da geliştirmek için çalışmalarımız devam etmektedir. Ayrıca Arapça ara yüzünde de halen pek çok eksiklik bulunmaktadır. Bu çalışmalarımız tamamlanınca Public Knowledge Project web sitesine gönderilerek tüm kullanıcıların bu çalışmalardan faydalanmaları sağlanacaktır.

$\mathrm{Bu}$ yazıda, Açık Dergi Sistemleri kullanılarak bir derginin nasıl kurulacağı ve dergimizin bu konuda yapmış olduğu yenilik ve geliştirmeler ele alınmıştır. Dergisi

Anahtar Kelimeler: Açık Dergi Sistemleri, Tarih Kültür ve Sanat Araştırmaları

\section{A sample application for Open Journal Systems: The journal of History Culture and Art Research}

\section{Summary}

The journal of History, Culture and Art Research founded within Karabuk University Research Center for History, Culture and Art began its life with the March 2012 edition. Our journal will serve all the sub-branches of social sciences, as per the foundation goals of the center. 
Thanks to the Turkish, English, French and Arabic interfaces, it will be possible to browse the journal which will be published four times a year in these four languages. Summaries of the articles in four different languages will be available.

The journal of History, Culture and Art Research has put a stake in the ground in this respect by introducing an Arabic Language add-on. Also many problems of the Turkish interface were solved through a careful endeavor. If demanded, it is possible to share our knowledge with the users of Open Journal Systems in Turkey. Our studies are still being carried out to further enhance the Turkish interface of the system. Still, there are still many flaws in the Arabic interface. When these studies are completed, the outcome will be sent to the Public Knowledge Project website so as to ensure the benefit of all users.

The information on how to set up a journal by using the Open Journal Systems and the innovations and improvements our journal has made in this respect are the context of this article.

Key words: Open Journal Systems, The journal of History Culture and Art Research

\section{Une application exemplaire dans l'édition de revue ouverte : Revue des Recherches en Histoire, Culture et Art}

\section{Résumé}

La revue des recherches en histoire, culture et art a commencé à paraître pour la première fois en Mars 2012. La revue - qui a été créée au sein du 'Centre des Recherches en Histoire, Culture et Art de l'Université de Karabük - publiera des travaux de recherches dans toutes les sous-branches des sciences sociales tout en respectant les objectifs du centre. La revue - qui sera publiée quatre fois par an - en ayant les interfaces en turc, arabe, anglais et français permettra au lecteur d'accéder à la revue par une de ces langues. Les articles publiés dans la revue auront des résumés dans quatre langues.

La revue des recherches en histoire, culture et art, en ajoutant en plus la langue arabe aux systèmes de revue ouverte, a effectué une innovation dans ce domaine. De plus, les problèmes existant dans l'interface turque de la revue se sont résolus grâce à un travail rigoureux. Nous voulons bien partager nos travaux avec ceux qui utilisent les systèmes de revue ouverte en Turquie. Nous continuons à améliorer l'interface turque du système mais il y a encore beaucoup de lacunes dans l'interface arabe. Lorsque ces travaux seront terminés nous enverrons notre travail au site d'internet de 'Public Knowledge Project' pour que tous les utilisateurs puissent profiter de ces outils techniques.

Dans cet article, nous examinerons comment une revue peut se constituer selon les systèmes de revue ouverte et les innovations que notre revue a mis en place dans ce domaine.

Mots-Clés : Revue des Recherches en Histoire Culture et Art

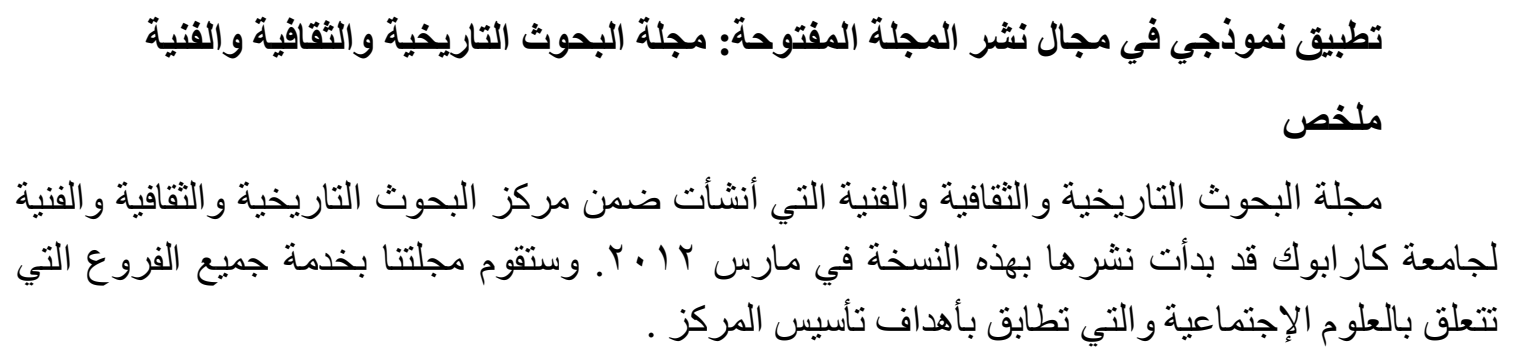




$$
\begin{aligned}
& \text { وقد حقت مجلة البحوث التاريخية والثقافية والفنية ولأول مرة بتحميل ملحقات اللغة العربية في نظام } \\
& \text { المجلات المفتوحة. بالإضافة إلى ذلك فإن كثيراً من المشاكل الموجودة في واجهة المجلة التركية قد أزيلت } \\
& \text { عن طريق دراسات دقيقة. ونحن نواصل العمل من أجل تطوير واجهة النظام العربي. وبعد انتهاء عملنا } \\
& \text { سيُرسل إلى موقع الويب (Public Knowledge Project) وبهذا سيتاح للمستعملين الإستفادة من هذا } \\
& \text { العمل. } \\
& \text { في هذه الكتابة ، تناولنا موضو ع كيفية تأسيس مجلة باستخدام نظام المجلات المفتوحة وتناولنا أيضا }
\end{aligned}
$$

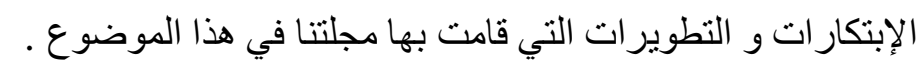

$$
\begin{aligned}
& \text { كلمات البحث: أنظمة المجلة المفتوحة، مجلة البحوث التاريخية و الثقافية والفنية . }
\end{aligned}
$$

\section{Giriş}

E-dergi yayıncılı̆̆ı, Dünyada ve Türkiye'de akademik çevreler tarafından hızla benimsenmiş bir olgudur. E-dergilerin basılı dergilere göre oldukça avantajlı yönleri vardır. Bunların içerisinde belki de en önemlisi yayımlanan yazıya internet vasıtasıyla dünyanın her köşesinden erişimin mümkün olmasıdır. Diğer avantajlı yönleri ise düşük maliyet, hızlı yayın, sayfa sınırlamasının olmaması vb. şeklinde sıralayabiliriz.

E-dergi yayıncılığında dünyada ve Türkiye'de tercih en önemli yazılımlardan birisi Open Journal System adı verilen açık kaynak kodlu yazılımdır. Açık Dergi Sistemleri adıyla Türkçeye çevrilen bu yazılım, bilginin yayılması adına ücretsiz olarak kullanıcıların hizmetine sunulmuştur.

Dergimizin yayınında da tercih ettiğimiz bu yazılımın kaynak kodlarını incelediğimizde, derginin İngilizce ara yüzüne oranla Türkçe ara yüzünün kaynak kodlarının büyük oranda eksik olduğu ve bazı kodların Türkçe tercümelerinde hatalar olduğu görülmüştür. Bu sistemi kullanan Türkiye'deki dergileri incelediğimizde ise dergilerin büyük bir çoğunluğunun, kodlar üzerinde hiçbir değişiklik yapmadan dergilerini mevcut yazılımı kullanarak yayınladıkları, geri kalanların ise ana sayfa ve önemli bölümlerde yer alan hatalı kodları düzelterek yayınlarını sürdürdükleri tespit edilmiş̧tir.

Kaynak kodların Türkçe ara yüzde eksik olması sistemi verimli olarak kullanmayı engellediği gibi, sisteme yabancı olan yazar, hakem ve okuyucuların sistemi kullanmalarını da zorlaştırmaktadır. Bunun yanında tercüme hataları ve İngilizce-Türkçe karakter uyumsuzluğu gibi ek problemleri de sayacak olursak bu sistemin Türkçe ara yüzünü geliştirmek için ciddi bir çalışma yapılması gerekliliği ortaya çıkmıştır.

Türkiye' de yakın tarihlerde pek çok yeni üniversitenin kurulması, özel üniversitelerin açılmaya devam etmesi ve online yayın yapmak isteyen ancak henüz bunu gerçekleştirememiş olan basılı dergilerin var oluşu, ileriki yıllarda Türkiye'de internet üzerinden online yayın yapan dergilerin sayısında hızlı bir artış olacağının habercisidir.

Dergilerini yeni kuracak olan meslektaşlarımızı cesaretlendirmek, yayınlanmakta olan dergilerdeki hatalı kodları düzeltmek isteyen meslektaşlarımıza yardımcı olmak ve hepsinin ötesinde E-dergi yayını yapmak isteyen Türkiye'deki akademisyenlerin para ve zaman kaybına uğramalarını engellemek için dergimizi kurarken yaşadığımız tecrübeyi paylaşmak ve bu konuda adım atmak isteyenlere yardımcı olmak adına bu yazımızda Açık Dergi Sistemlerini (OJS) tanitmak istiyoruz. 


\section{Açlk Dergi Sistemleri}

Açık Dergi Sistemleri (OJS), Public Knowledge Project tarafından geliştirilmiş açık kaynak kodlu bir yazılımdır. Public Knowledge Project (PKP), British Columbia, Simon Fraser ve Stanford Üniversitelerinin birlikte oluşturdukları açık kaynak kodlu, ücretsiz yazılım ürünleri geliştirmeyi hedefleyen ve kâr amacı gütmeyen bir projedir. Açık Dergi Sistemlerinin yanında, aynı proje kapsamında geliştirilmiş farklı yazılımlar da mevcuttur (http://pkp.sfu.ca/?q=ojs).

Açık Dergi Sistemleri dünya çapında ücretsiz olarak kullanılan bir sistemdir. Sistemin en yaygın olarak kullanıldığı kıtalar Kuzey ve Güney Amerika kıtaları ile Avrupa kıtasıdır. Türkiye'nin de dahil olduğu, Ortadoğu ve Asya kıtası ise bu sistemin en az kullanıldığı bölgeler olarak göze çarpmaktadır (http://pkp.sfu.ca/ojs-geog).

\section{Yazılım Lisansı}

Açık Dergi Sistemleri, "GNU General Public License" kapsamında ücretsiz bir yazılımdır. Yazılımı kullananlar ve dağıtanların, bu lisansın şartlarını bilmeleri gerekir. Programın ana dizini içerisinde yer alan docs klasörü içindeki copying dosyası, bu lisans ile ilgili ve programın telif hakları ile ilgili kapsamlı bilgi içermektedir.

Burada yazılı olan şartları kısaca özetleyecek olursak; programın aynen kopyalanarak dağıtılabileceği, programı kullananların üzerinde değişiklik yapabilecekleri, bu programın üçüncü şahıslara verilmesi durumunda onların da aynı haklara sahip olacağı, program ücretsiz olduğu için herhangi bir garantisi olmadığı ve bu lisansın sahibi olan The Free Software Foundation kurumunun lisans üzerinde değişiklik yapma hakkı bulunduğu gibi hususları sayabiliriz.

\section{Derginin Kurulumu}

Açık Dergi Sistemleri yazılımı, bu yazılımın geliştiricisi olan Public Knowledge Project web sitesinden indirilebilir. Web sitesinin Download bölümünde yazılımın önceki sürümleri ve bu sürümlere ait notlar yer almaktadır. Yazılımın son sürümü 30/06/2011 tarihli OJS 2.3.6 sürümüdür. Yapılması gereken şey elbette yüklemenin yapıldığı tarihte yüklenmiş olan son sürümün indirilmesi ve kurulmasıdır.

Dergi sunucuya yüklendikten sonra web adresi üzerinden dergiye erişim mümkün hale gelecektir. Bu aşamadan sonra yönetici kullanıcı adı ve şifresi kullanılarak sisteme giriş yapılabilir.

Sisteme giriş yapıldıktan sonra dergi ile ilgili bazı işlemlerin yapılması gerekmektedir. $\mathrm{Bu}$ işlemleri kısaca şu şekilde özetleyebiliriz.

1. Sisteme ilk giriş yapıldığında bizim "Kullanıcı Sayfası" olarak çevirdiğimiz "User Home" sekmesine tıklanarak ilk önce Site Yönetimi bölümüne gidilir ve buradaki bilgiler doldurulur. Açık Dergi Sistemleri, üzerinde birden fazla derginin kurulabilmesine imkan sağlayan bir sistemdir. Ancak eğer sistem üzerinde sadece bir dergi bulunacaksa o zaman Site Yönetimi bölümünde bulunan dergiye yönlendirme seçeneği kullanılarak doğrudan dergiye erişimin mümkün hale getirilmesi faydalı olacaktır.

2. Daha sonra dergi yönetimi bölümüne gidilerek derginin ayarları yapılır. Burada önemli bir problem vardır. Açık Dergi Sistemlerinin mevcut sürümünde (2.3.6) Türkçe ara yüze ait pek çok eksik kod bulunmaktadır. Kodların eksik olması 
sistem üzerinde kullanmanız gereken pek çok özelliği ya görmenizi engellemekte ya da kodun tanımı yerine kendisini göstererek işinizi zorlaştırmaktadır. Eğer birinci adımda kullanacağınız dil seçenekleri içerisinde İngilizceyi seçmişseniz dergi kurulumunu yaparken hatalı kod bulunmayan İngilizce ara yüzü kullanarak eksik bölümlerin neler olduğunu tespit edebilir ya da hatalı görünen kodların tanımlarını bulabilirsiniz.

\section{Hatalı Kodların Düzeltilmesi}

Derginin farklı dillere ait dosyalarının bulunduğu iki farklı temel dizin bulunmaktadır. Bunlar, lib/pkp/locale/tr_TR dizini ile locale/tr_TR dizinleridir. Bu dizinlerde bulunan .xml uzantılı dosyaları Dreamweaver ya da Editplus gibi daha basit bir program kullanarak açabilir ve üzerlerinde değişiklik yapabilirsiniz. Bu dosyaların İngilizce orijinallerini görmek için en_US dizininde yer alan aynı isimli dosyaları kullanabilirsiniz. İngilizce ve Türkçe dosyaların karşılaştırılması neticesinde Türkçe dosyada hangi satırların eksik olduğu ya da İngilizce orijinal metnin Türkçeye nasıl çevrildiği de görebilirsiniz.

Ancak, bu dosyaların İngilizce dosyalarla karşılaştırılarak eksik satırlarının tamamlanması sistemdeki bütün problemleri halletmeyecektir. Eksik kodları tamamlamanıza rağmen sistemin ana sayfasında yer alan eklentilerde (plugins) eksik kodlardan kaynaklanan hatalı görünümler devam edecektir. Bunun nedeni Plugins dizini altında yer alan eklentilerin hiçbirisinde tr_TR klasörünün bulunmayışıdır. Basit bir çözüm olarak kullanmak istediğiniz eklentinin ana dizininde yer alan en_US dizinini kopyalayarak tr_TR adiyla yeniden kaydedebilirsiniz. Bu klasör içerisinde yer alan .xml uzantılı dosya üzerinde çevirisini yaptığınız İngilizce kelimeler artık Türkçe olarak gözükecektir. Yalnız bu durumda karşınıza İngilizce-Türkçe karakter uyumsuzluğu çıkabilir. Bu sorunu aşmak için değişikliklerinizi Dreamweaver programı ile yapmanız ya da Türkçe karakter kullanmamanız gerekebilir.

Açık Dergi Sistemleri ile birlikte kullanılabilecek pek çok eklenti bulunmaktadır. Tarih Kültür ve Sanat araştırmaları dergisinde bu eklentilerden sadece block plugins grubunda yer alan üç eklenti kullanıldığg için eklentiler üzerinde ciddi bir çalışmaya gidilmemiştir. $\mathrm{Bu}$ nedenle bizimle aynı dosyaları kullansalar bile kendi dergilerine farklı eklentiler kurmak isteyen kullanıcıların yukarıda anlattığımız hususu göz önünde bulundurmaları gerekir.

\section{Yeni Bir Dil Eklenmesi}

Açık Dergi Sistemlerinin mevcut sürümünde 23 adet dil klasörü bulunmaktadır. Ancak bu dillerin pek çoğu halen daha geliştirilme aşamasındadır. Sistemde yer alan dillerin hangi ölçüde tercüme edildiği Public Knowledge Project web sitesinde ayrıntılı bir şekilde yer almaktadir.

Tarih Kültür ve Sanat Araştırmaları dergisine, burada yer alan dillere ek olarak Arapça dili eklenmiştir. Sisteme bunun dışında herhangi bir dilin eklenmesi de mümkündür. Bunu yapmak için registry dizininde yer alan locales.xml dosyasına bir satır eklemeniz gerekecektir. Örneğin, bu dosya içerisinde yer alan satırlardan birisini kopyalayarak alt tarafa yapıştırır ve burada yazan dilin adını değiştirerek eklemek istediğiniz dilin adını yazarsanız sisteme yeni bir dil yüklemiş olursunuz.

Bu kısmı tamamladıktan sonra eklemiş olduğunuz dile ait yerel dosyaları oluşturmak için lib/pkp/locale dizini ile locale dizininde dil klasörleri oluşturmanız gerekecektir. Bunu yapmak için bu dizinlerde yer alan en_US klasörlerini kopyalayarak oluşturduğunuz dile göre yeni bir ad vererek aynı dizine yapıştırabilirsiniz. Bundan sonra yapmanız gereken şey bu 
klasörlerde yer alan .xml uzantılı dosyalar içinde yer alan etiket yazılarını yeni eklediğiniz dile çevirmek olacaktır.

\section{Bilgi Girişlerinin Yapılması}

Dergi ile ilgili bilgi girişleri bizim "Kullanıcı Sayfası" olarak tercüme ettiğimiz "User Home" sekmesi kullanılarak yapılır. Bu başlık altında bulunan maddeleri şu şekilde siralayabiliriz:

\section{- Yönetim Sayfaları (Management Pages) Bölümü}

»Duyurular (Announcements): Bu bölümde ana sayfadaki duyurular sekmesi altında görülecek olan duyuruların girişi yapılır. İşlem yapılması zorunlu değildir.

» Dosya tarayıcı (Files Browser) : Bu bölümde sisteme yüklenmiş olan makalelerin bulunduğu klasörler yer almaktadır. İşlem yapılması zorunlu değildir.

» Bölümler (Journal Sections): Bu bölümde akademik bir dergide bulunması gereken bölümler kullanıcı tarafından oluşturulur. Mesela Makaleler, Editöryal Yazılar, Kitap Değerlendirmeleri vs. Bu bölümlerden bazılarının hakem değerlendirmesi dışında bırakılması mümkündür. Ayrıca bölüm editörlerinin ataması da bu bölümden gerçekleştirilir. Bu işlemler yapılırken diğer dillere de aynı anda kayıt yapılmalıdır. Örneğin Türkçe yazdığınız bölümleri form dili bölümünden İngilizce seçeneğini seçerek İngilizce bölümüne de kaydetmek gibi.

» Değerlendirme Formları (Review Forms): Bu bölümde hakemlerin değerlendirmelerini yaptıktan sonra dolduracakları form yine kullanıcı tarafından oluşturulmaktadır. Form doldurulurken farklı dillerin aynı anda doldurularak kaydedilmesi önemlidir. Çünkü kaydedilen form, bir defa kullanıldıktan sonra artık üzerinde değişiklik yapılamaz. Hakem formunu oluşturmak için önce forma bir isim verilir. Daha sonra hemen üst satırda yer alan form maddeleri tıklanarak maddeler oluşturulur. Maddelerin yazı kutucuğu şeklinde görülmesi zorunlu değildir. Radyo düğmeleri gibi farklı seçenekleri kullanmak mümkündür.

» Diller (Languages): Bu bölümde dergi için seçtiğiniz dilleri görebilir ve bu dillerin hangi özelliklerini kullanmak istediğinizi belirleyebilirsiniz.

»Yönetici Listesi (Masthead): Bu bölümde editör, editör yardımcısı, bölüm editörü, hakem kurulu ve yayın kurulu gibi başlıklar oluşturarak bu başlıkların altını doldurabilirsiniz.

» E-posta şablonları (Prepared Emails): Bu bölümde, yazışmalarda kullanacağınız hazır e-posta şablonları bulunmaktadır. Bunların içeriğinin buradan değiştirilmesi mümkündür.

» Okuma araçları (Reading Tools): Bu bölümde makalenin hangi bölümlerinin ne şekilde görüleceği ile ilgili ayarlar yapılabilir.

»Ayarlar (Setup): Dergi ile ilgili en önemli ayarların yapıldığı bölüm burasıdır. 5 basamaktan oluşur.

1. Ayrıntılar: Bu bölüm derginin adı, ISSN numarası, dergi iletişim bilgileri gibi bazı bilgilerin girildiği bölümdür.

2. Politikalar: Derginin ilgi alanları, makalelerin ne şekilde ve ne kadar süre içerisinde değerlendirildiği ve diğer dergi politikaları ile ilgili ayarların yapıldığı bölümdür. 
3. Başvurular: Yazarların dergiye gönderecekleri makalelerde uyması gereken yazım kuralları, telif hakları vb. bilgilerin düzenlendiği bölümdür.

4. Yönetim: Dergi içeriğine erişim izni, dergi sitesini kullanım ile ilgili izin ve kısıtlamalar, derginin yılda kaç kez yayınlanacağı gibi bazı özelliklerin tanımlandığı bölümdür.

5. Görünüsş: Derginin görünümüyle ilgili tüm ayarların yapıldığı bölümdür. $\mathrm{Bu}$ bölüm kullanılarak dergiye logo eklenebilir. Başlık metni yerine grafik yüklenebilir. Giriş sayfasının ortasına bir resim yerleştirilebilir. Anasayfaya yeni bir yönlendirme barı eklenmesi de bu bölümden yapılır. Bunun dışında farklı temalar seçilerek derginin görünümü değiştirilebilir. Derginin görünümü ile ilgili aşağıda ayrıntılı bilgi verilecektir. Ana sayfada bulunan eklentilerin kaldırılması ve eklenmesi de bu bölümden yapılır. Orta bölüme toplanan eklentiler kaldırılmış olurlar. Burada bulunan eklentiler isteğe bağlı olarak ana sayfanın sağ ya da sol tarafındaki kenar çubuğuna gönderilir. Anasayfada kenar çubuğunda yer alacak bilgi notları da buradan girilir.

» İstatistikler ve Raporlar (Stats \& Reports): Dergi ile ilgili bir takım istatistiki bilgilerin yer aldığı bölümdür.

» Ödemeler (Payments): Kullanılması zorunlu bir bölüm değildir. Dergilerini ücretlendirmek isteyenler kullanabilir. Bizim yaptığımız çalışmada da bu bölümün bir kısmı tamamlanmış bir kısmı ise henüz tamamlanmamıştır.

» System Plugins (System Plugins): Sisteme yeni bir eklenti yüklenmesi ya da var olan eklentinin silinmesi bu bölümden gerçekleştirilir.

»Verilerin sistemden alınması/eklenmesi (Import/Export Data): Dergimizde bu bölümün eksik kodları kısmen tamamlanmıştır. Birtakım faydalı özellikler içermektedir. Örneğin, sisteme kaydedilen kullanıcılara otomatik olarak bir e-posta gönderilmesi seçeneği bu bölümde mevcuttur.

\section{- Kullanicılar Bölümü}

$\mathrm{Bu}$ bölümde dergiye yeni üye kaydedilmesi, kayıtlı olan üyelere yeni roller atanması gibi işlemler gerçekleştirilebilir. Örneğin dergiye yazar olarak kayıtlı olan bir kullanıcının hakem olarak kaydının yapılmasının istenmesi durumunda bu bölüme başvurulur.

\section{- Roller Bölümü}

Bu bölüm dergiye kayıtlı olan tüm kullanıcıların yer aldığı bölümdür. Buradaki farklı rol seçenekleri seçilerek yeni roller eklenebileceği gibi kayıtlı kullanıcıların bilgilerinin düzeltilmesi ve değiştirilmesi gibi işlemler de gerçekleştirilebilir. Burada yer alan kullanıcılara e-posta gönderilmesi mümkündür. Aynı zamanda herhangi bir kullanıcı adına sisteme giriş yapılması da mümkündür. Örneğin sistemi kullanmakta zorlandığı için değerlendirmelerini size kişisel e-postası ya da normal posta seçeneğini kullanarak gönderen bir hakemin değerlendirmelerini sisteme girmek için bu bölüm kullanılabilir. 


\section{Dergi Görünümünün Değiştirilmesi}

Dergi kurulduktan sonra en önemli meselelerden birisi elbette derginin görünüm şeklidir. Yazı puntolarının rahatlıkla okunabileceği, okuyucunun ilgisini çekecek ve beğenisini toplayacak bir dergi görünümü elbette tüm dergilerin arzu edeceği bir husustur.

Açık dergi sistemleri, kullanıcıların seçebileceği 10 kadar temayı sisteme otomatik olarak yüklemiştir. $\mathrm{Bu}$ temalardan birisini seçerek derginizin görünümünü anında değiştirebilirsiniz. Tema seçme işleminin yukarıda bahsi geçin Görünüsş bölümünden yapılması mümkündür. Ancak sistemde yüklü olan bazı temaların Türkçe karakter sorunu vardır. Mesela bazı temalarda sizin sisteme küçük harf olarak yazdığınız etiket yazıları otomatik olarak büyük harfe çevrilmektedir. Bu durumda örneğin İngilizce de küçük olarak yazıldığında “ $\boldsymbol{i}$ ” büyük yazıldığında ise " $\boldsymbol{I}$ ” şeklinde yazılan harfle ilgili sorun yaşamanız kaçınılmazdır. Bu sorunu gidermek için hatalı olduğunu gördüğünüz etiketlerin yukarıda adreslerini verdiğimiz iki dil klasörü için yer alan .xml uzantılı dosyalardan bulunarak büyük harflerle yazılması sorunu kısmen çözecektir.

Diğer bir çözüm yolu ise plugins dizininde yer alan themes klasöründen seçmiş olduğunuz temayı bulmaktır. Burada seçmiş olduğunuz tema klasörünün içinde aynı ismi taşıyan .css uzantılı dosyayı açtığınızda "text-transform: uppercase;" yazılı komut satırını silerseniz büyük harfe dönüştürme işlemini engeller ve kısmi bir çözüm sağlamış olursunuz.

Ayrıca eğer sayfadaki yazıların küçüklüğünden şikayetçiyseniz block eklentileri (plugins) içerisinde yer alan Fontsize eklentisini ana sayfaya yükleyebilirsiniz. Eğer Font büyüklügüünun doğrudan sayfada gerçekleşmesini istiyorsanız açmış olduğunuz tema dosyasındaki main başlı̆̆ 1 altında yer alan ve 12 puntoya karşılık gelen "font-size: 1.0em;" ifadesindeki değeri 1.1, 1.2 gibi değerlerle değiştirebilirsiniz. Eğer kullandığınız temanın main başlığı altında bu komutu bulamazsanız oraya bu komutu kopyalayabilirsiniz. Aynı şekilde burada yer alan hexadecimal renk kodlarını istediğiniz kodlarla değiştirerek farklı renk tonlarında görünüm elde etmeniz de mümkündür.

Bütün bu anlattıklarımız, beğenmiş olduğunuz tema üzerinde değişiklik yapmak istediğinizde geçerlidir. Bunun dışında internet üzerinde de paylaşıma açılmış güzel tema örnekleri mevcuttur. .css uzantılı bu dosyaları bilgisayarınıza indirdikten sonra mevcut temalarınıza ekleyebilir ya da herhangi bir tema dosyasının içeriğini değiştirebilirsiniz. Elbette bütün bu işlemlerin bir program yardımıyla ve profesyonelce yapılması daha güzel olur.

\section{Makalelerin Yüklenmesi ve Editöryal İşlemler}

Açık Dergi Sistemleri, bir makalenin gönderilmesinden yayımlanmasına kadar bütün sürecin online olarak gerçekleştirilebilmesini kolaylaştıran bir yazılımdır. Ancak sisteme yabancı olan bazı yazar ve hakemlerden aldığımız geri dönütler, mevcut yazılım üzerinde bazı küçük revizyonların yapılmasının gerekli olduğunu göstermiştir.

Konu ile ilgili şöyle bir örnek verebiliriz: Dergiye makale göndermek isteyen yazarların öncelikle dergiye yazar olarak üye olmaları gerekir. Üyelik kaydı bulunanlar kullanıcı adı ve şifrelerini kullanarak sisteme giriş yaparlar. Sisteme giriş yapan yazar, karşısına çıkan sayfadaki "yeni başvuru" linkine tıklayarak yazısını gönderme adımını başlatır. Ancak, bazı yazarların makale göndermek için bu linkin tıklanması gerektiğini anlamayarak bizden yardım istemesi üzerine, İngilizce orijinali "new submission" olan bu link yazısı bizim tarafımızdan değiştirilerek "MAKALE GÖNDER” şeklinde büyük harflerle 
ve anlaşılabilir bir ifadeyle yazılmış ve bundan sonra yazarlardan bu konuda bir yardım talebi gelmemiştir.

Benzer sorunlar hakemlerle ilgili bölümde de vardır. Mesela hakem sayfasında değerlendirme formunu açmak için konulan ikonun tıklanması gerektiği ile ilgili hiçbir açıklayıcı ifade olmaması nedeniyle bazı hakemler bu konuda bizden yardım istemiştir. Bunun üzerine bizim kullandığımız sistemde bu bölümlere hakemlerin yapmaları gerektiği işlemleri açıklayan bazı ifadeler eklenerek kullanımın kolaylaşması sağlanmıştır.

Sisteme yabancı olanların ilk başlarda yabancılık çekmelerini istisna edecek olursak, Açık Dergi Sistemleri, kullanımı oldukça rahat ve çok işlevli bir yazılımdır. Makalelerini sisteme yükleyen yazarlar makaleleri ile ilgili editöryal süreci sistem üzerinden takip edebilmektedir. Sisteme yüklenen yazılar editör sayfasında gözükmekte ve editör tarafından hakemlere gönderme işlemleri başlatılmaktadır. Yazının editör tarafından herhangi bir editör yardımcısına havale edilerek iş yükünün bölüşülmesi de mümkündür. Hakemlere gönderilen yazılar gerekli düzeltmeler yapıldıktan sonra tekrar sisteme geri yüklenmektedir. Böylece gönderilen makalelerin kısa bir süre içerisinde değerlendirilmesi ve yayına hazırlanması mümkün olmaktadır.

\section{Sonuç}

Açık Dergi Sistemleri, hakemli yazıların tüm yayın sürecinin kolaylıkla yönetilebildiği ve bu süreçte yer alan tüm işlemlerin online gerçekleştirilebildiği bir sistemdir. Sistemin ücretsiz olarak kullanıcıların hizmetine sunulması ve farklı dillerde erişim imkanının bulunması gibi özellikleri nedeniyle tüm dünyada akademik çevreler tarafından hızla benimsenmiş ve kullanıcı sayısı binlerle ifade edilmeye başlanmıştır.

Akademik dergi yayıncılığında açık erişim politikasını benimseyen Tarih Kültür ve Sanat Araştırmaları Dergisi de Açık Dergi Sistemlerinin (OJS) 2.3.6 sürümünü kullanmaktadır. Ancak mevcut sürümdeki Türkçe dil eklentisinde yer alan sorunlar giderilmiş, eksik kodlar sisteme eklenerek tercüme edilmiş ve daha önceki sürümlerde yer alan bazı tercümelerde değişiklikler yapılmıştır. Ayrıca sisteme ilk defa Arapça dil eklentisi de yüklenmiştir. Tarih Kültür ve Sanat Araştırmaları Dergisi bu nitelikleriyle bir ilk olma özelliğine sahip olmuştur. Dergiyi oluştururken edindiğimiz tecrübeler, eksik kaynak kodlarla ilgili yapmış olduğumuz düzenlemeler ve kod etiketlerinin tercüme edilmesiyle ilgili yapmış olduğumuz tüm çalışmalar talep eden kullanıcıların istifadesine açıktır.

\section{Kaynaklar}

http://pkp.sfu.ca $(07 / 03 / 2012)$.

http://www.gnu.org/licenses/gpl-howto.html (07/03/2012). http://kutaksam.karabuk.edu.tr/index.php (07/03/2012) 